\title{
Risk Influence Modeling of Recent Developments in Helicopter Safety on the Norwegian Continental Shelf
}

\author{
T. Kråkenes, S. Håbrekke \& I.A. Herrera \\ SINTEF Technology and Society, Safety Research, Trondheim, Norway
}

\begin{abstract}
Helicopter Safety Study 3 (HSS-3) is a Norwegian joint industry research project established in 2008. The main objectives of the study are to assess the risk level associated with offshore helicopter transportation, propose indicators to monitor safety, and identify safety measures for further improvement. The study will address risk through two complementary approaches: one using risk influence modeling and one focusing on resilience engineering. This paper presents preliminary results from a comprehensive review of recent developments relevant for helicopter safety. These developments affect a set of risk influencing factors (RIFs - including technical, human and organizational factors) in an existing risk influence model in two ways. Firstly, the model is modified to include new aspects that have emerged in the study period 1999-2008. Secondly, the developments will form the basis for expert judgment sessions to update the risk contribution of each RIF in the model.
\end{abstract}

\section{INTRODUCTION}

The development in the safety domain has been remarkable since the early days of oil production in the 1970s, resulting in the very high safety standards in the industry today. On the Norwegian Continental Shelf (NCS), helicopter accidents are rare events, and no fatal accidents have occurred in the last decade. However, the absence of accidents and the observed reduction in statistical risk for personnel traveling with helicopter on the NCS do not necessarily reflect the actual risk level. Helicopter transportation is regarded as a major contributor to risk to personnel working in the offshore oil and gas industry. Helicopter safety therefore remains a major issue of concern in the industry today, and the emphasis on safety is ever-increasing.

Personnel are transported over long distances; e.g. Ekofisk, the oilfield with the most helicopter traffic on the NCS, lies $300 \mathrm{~km}$ offshore. Offshore activity has gradually expanded from the North Sea into regions further north, the Norwegian Sea and the Barents Sea. The weather conditions in the northern regions are often harsh and demanding, making helicopter operations a challenging task. In contrast to many regions elsewhere in the world, all helicopters operating on the NCS are twin-engine, two-pilot aircraft.

The Helicopter Safety Study 3 (HSS-3) is a joint industry effort by the main oil companies operating on the NCS. Main objectives of the study are to as- sess the risk level associated with offshore helicopter transportation, propose indicators to monitor safety, and identify safety measures for further improvement. The study will address risk through two complementary approaches: a "risk approach" using risk influence modeling, and a "safety approach" focusing on resilience engineering. The project was established in 2008, and final results from HSS-3 will be delivered early in 2010. The study is an update of two previous studies focusing on the periods 199098 (Hokstad et al. 1999, 2001) and 1966-90 (Ingstad et al., 1990) respectively. The HSS-3 focus of analysis is on the 10 year period 1999-2008, which in this paper is referred to as the study period. The ambition is that HSS-3 will set a reference standard for methodologies used to analyse risk, to identify and assess risk-reduction measures.

The first phase of the HSS-3 study consists of a comprehensive review of relevant literature and studies, accident/incident/deviation reports and statistics in the study period, including interviews with key participants in the industry. There are two main results from this phase of the study. The first result is an updated statistical risk picture on the NCS based on the historical development in the study period; this is not presented in the paper. The other result, and the main topic of this paper, is an overview of recent safety-related developments in helicopter operations in the study period; these developments are described in section 2 . 
The developments are assumed to have some effect (positive or negative) on the risk; the effect working through a set of risk influencing factors (RIFs - including technical, human and organisational factors) in a risk influence model. A RIF is a set of relatively stable conditions influencing the risk that may be improved or worsened by specific actions.

The developments affect the RIFs in two ways. Firstly, the model is modified to include new aspects that have emerged in the study period; this is discussed in section 3. Secondly, the developments will form the basis for expert judgment sessions to update and quantify the risk contribution of each RIF in the model; this is the focus of sections 4 and 5 .

An important analysis assumption is that accidents and incidents are the result of a combination of various factors, so that improvement of those factors could prevent accidents. In this view the RIF modelling approach seems reasonable in order to describe cause-effect relationships. Risk influence modelling using RIFs and influence diagrams is an alternative to more detailed modelling using reliability techniques like fault trees and event trees. The risk influence modelling approach has proven useful in the previous study (HSS-2) (Hokstad et al. 1999, 2001), as well as in other transport related studies at SINTEF, see e.g. Hokstad \& Dahle (1998). Other recent examples of offshore applications of a RIF approach include the BORA method (Sklet et al. 2005) and the work of Røed et al. (2009).

An introduction to modelling with influence diagrams can be found in e.g. Howard and Matheson (2005).

\section{RECENT DEVELOPMENTS IN HELICOPTER OPERATIONS}

This section lists and describes briefly the identified main developments relevant for helicopter safety in the study period 1999-2008. The list results from a comprehensive review of relevant literature and studies, accident/incident reports and statistics, as well as interviews with key participants in the industry (pilots, engineers, managers and ATC-personnel). Some preliminary evaluations have been done of the identified changes. The developments considered to have the most impact on the RIFs are described in section 2.1 and 2.2. The developments considered to be less significant with respect to safety are found in section 2.3. Each of the developments may impact one or more of the RIFs (for frequency and/or consequence); see Chapter 3.

\subsection{Important developments with assumed risk- reducing effect}

1. New helicopters. The helicopter operators on the NCS have put in service the modern helicopter types Sikorsky S-92 and Eurocopter EC225 during the study period. This new equipment is believed to enhance operations on all levels, including safety. New helicopters also represent some drawbacks, e.g. nuisance alarms.

2. HUMS (Health and Usage Monitoring System) is a system for technical condition surveillance (e.g. vibration monitoring) that has continuously improved during the study period. Analysis of HUMSdata may give early warnings of anomalies and deviation not easily detectable by other means. The use of HUMS is widely considered as an important improvement to helicopter safety.

3. M-ADS (Modified Automatic Dependent Surveillance) is a satellite-based system for tracking helicopters outside radar coverage. The equipment is important for avoiding traffic conflicts and locating helicopters after accidents. There is, however, a significant challenge in maintaining the system due to delivery problems, and a new solution is currently sought for.

4. ACAS (Airborne Collision Avoidance System) is a collision alerting system in regular use on fixedwing aircraft. For helicopters, only ACAS I is used in Norway, but further developments are expected. Mid-air collision is the accident type with the highest consequence in terms of loss of lives.

5. Standardisation of procedures. There has been a great emphasis on standardisation of procedures for helicopter operation during the study period.

6. FDM (Flight Data Monitoring) is a system to identify, quantify and assess risk based on logging of flight information. Flight data analysis makes it possible to detect deviations from normal operations and normal procedures, thereby pinpointing areas of improvement.

7. Increased reporting of events. In July 2007 a new reporting regulation was introduced, which requires reporting of all events in a more systematic way. Reports shall also be filed from ground and maintenance personnel (i.e. not only from operation), as well as from ATC personnel.

8. Simulators. The amount of simulator training has increased, and the quality of the simulators has improved during the study period. Simulator training is a valuable supplement to ordinary training, allowing safe exposure to difficult and dangerous situations. With increased logging of flight data, it will be possible to reproduce real flight situations in the simulator.

9. Radar coverage. The areas with radar coverage on the NCS have been extended during the period, and there is more to come in the time ahead. Radar coverage eases helicopter traffic separation and in- 
creases the chances of locating a helicopter in case of an accident.

10. Helideck operations. Several improvements have taken place within helideck operations during the study period. New helideck manuals have been issued, helideck design requirements have been improved and helideck motion monitoring systems have been introduced.

11. Air weather service. Co-operation between the industry, the NCAA and the Meteorological Office has improved, and a new set of regulations concerning the weather service has been introduced.

12. Survival suits. New survival suits have been developed with e.g. improved thermal performance and personal locating beacon.

\subsection{Important developments representing potential safety challenges}

13. Moving rigs. The number of moving facilities has increased during the study period. This is mostly due to the willingness to explore and exploit smaller fields. Helideck operations (i.e. landing, parking and take-off) on a moving helideck are much more challenging than operations on a stationary helideck.

14. Activity in the northern regions. Activity on the NCS has gradually moved north from the North Sea via the Norwegian Sea to the Barents Sea. The weather conditions in the north are more demanding (low temperatures, darkness, icing, polar lows, etc.).

15. New participants on the NCS. A range of new actors have found their way to the NCS during the study period, also including new helicopter operators. There is a concern that some of the new participants - typically small and partly foreign oil and gas companies - are possibly less likely to adhere to the high safety standards achieved on the NCS through continuous work for decades.

16. Relocating of the NCAA. The splitting and subsequent relocating of the NCAA from the capital Oslo to the northern town of Bodø in 2006 led to a significant loss of personnel. For some time, this affected continuity, capacity and the quality of services provided. Core competence on heavy helicopters was lost, and helicopter inspectors were lacking.

\subsection{Other developments}

17. New materials. There is a development towards the use of lighter and stronger composite materials at the expense of metal. This is supposed to improve both economy and safety.

18. De-icing. Icing is a well-known problem in the north. There has been some development in deicing systems in the study period.

19. Differential GPS (Global Positioning System) has been recommended as a primary approach aid. GPS is not yet approved as a primary navigation aid, but is in use, especially outside controlled airspace.
20. Ground Proximity Warning System (GPWS) and Enhanced GPWS gives an alert when the helicopter is too close to the terrain or obstacles.

21. ICT in the cockpit. The way information is presented to the pilots has changed dramatically. The amount of information has increased considerably due to developments in digitalisation and processing power.

22. New procedures for approach and landing are introduced gradually as experience is gained from specific incidents, or new equipment is introduced.

23. Pilot experience requirements seem to be relaxed in a situation of rising pilot demand and reduced availability of experienced personnel.

24. Helicopter Flight Information Service (HFIS). There is a tendency towards moving HFIS personnel from the facilities to land in order to cut costs.

25. Safety Management System (SMS) is an ICAO recommendation and soon to be an EASA requirement for the helicopter operators.

26. Organisation and ownership. The two main helicopter operators on the NCS have got new and foreign owners during the last decade.

27. EASA (European Aviation Safety Agency) is the new organisation for civil aviation within the European Union. EASA was established in 2002, and all adhering nations have committed to implement EASA regulations into national regulations.

28. Helideck inspection remains an area of concern for the industry. The responsibility for inspection is unclear and it seems difficult to change the situation.

29. Splitting of the NCAA. In 2000 the NCAA was separated from the Air Traffic and Airport Management, clarifying responsibilities and roles in the organisations.

30. The Accident Investigation Board (AIBN) was reorganised in 2005, turning the board into a commission of inquiry for the entire public transport sector.

31. Establishment of the Petroleum Safety Authority (PSA). In 2004 the PSA was separated from the Petroleum Directorate, clarifying responsibilities and roles in the organisations.

32. Contracts and competition. Increased competition among the helicopter operators and the arrival of new operators have put pressure on economy and safety margins in the operations.

\section{RISK INFLUENCE MODEL}

The risk influence model in the HSS-3 project is a further development of the risk influence model used in the previous study (HSS-2). In this section the updated qualitative risk influence model is briefly described. A short introduction to how risk is quantified is also given; confer Hokstad et al. (1999, 2001) for a detailed description of the risk model. 


\subsection{Qualitative risk model}

The risk influence model is based on a number of Risk Influencing Factors (RIFs) arranged in influence diagrams. A RIF is a set of relatively stable conditions influencing the risk. It is not an event, and it is not a state that fluctuates over time. RIFs are thus conditions that may be influenced or improved by specific actions. The RIFs are split into two broad categories of risk frequency influencing factors and risk consequence influencing factors, and are organised in three levels as follows (Figure 1):

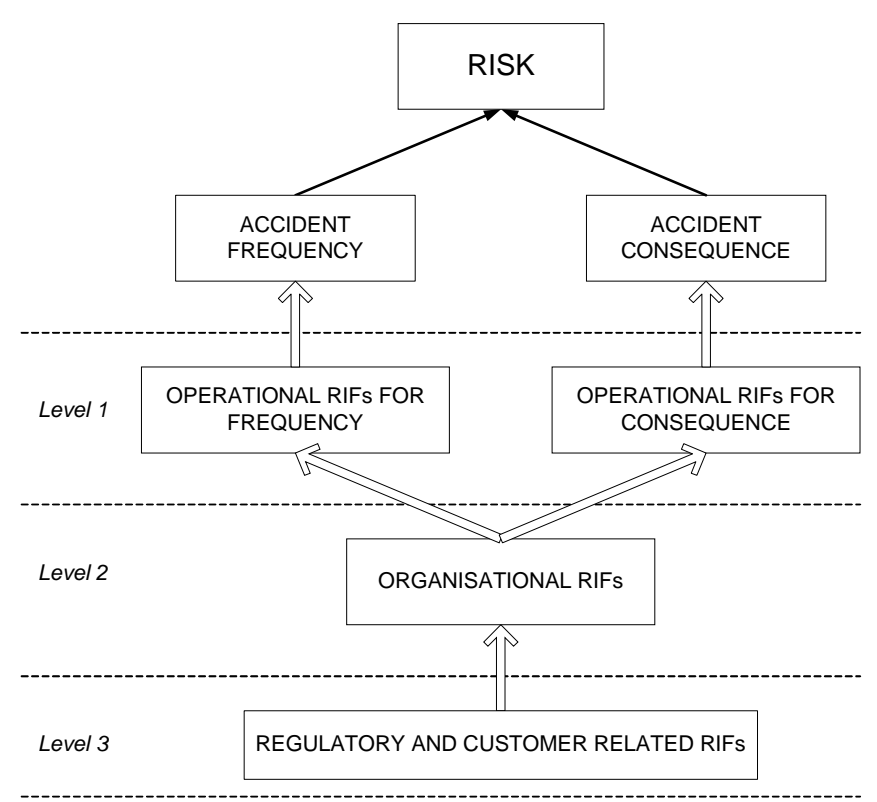

Figure 1. Outline of the general risk influencing model.

Operational RIFs (Level 1) are risk influencing factors related to activities necessary to provide safe and efficient offshore helicopter transport on a day to day basis. The activities include conditions related to requirements for aircraft technical dependability, state of aircraft operational dependability and provision of necessary external services.

Organisational RIFs (Level 2) are risk influencing factors related to the organizational basis, support and control of running activities in helicopter transport. These factors are related to helicopter manufacturers and operators, helideck/heliport operators, air traffic/navigation services and search and rescue services.

Regulatory and customer related RIFs (Level 3) are risk influencing factors related to the regulating and controlling activities from authorities and customers.

The detailed influence diagrams for accident frequency and accident consequence are shown in Figures 2 and 3 respectively. Each box at levels 1-3 in the figures represents a RIF, and the arrows represent influences between the RIFs. Most of the arrows in the diagrams go from one level to the next level above. This is not a requirement, however, as demonstrated e.g. by the arrows from the National Authorities RIF (level 3) to the ATM RIF (level 1) indicating a direct influence from authorities to operation. Observe that, in order to reduce the number of arrows and to simplify the figure, arrows are not drawn directly from National Authorities (NA) to the RIFs two levels above. Instead, the relevant influences are indicated by small boxes titled $N A$, connected directly to the RIFs in question.

Furthermore, the operational RIFs at level 1 are grouped in main causes (frequency RIFs) and main impacts (consequence RIFs). These groups of RIFs may be considered as "super-RIFs" at a Level 0 . At a later stage in the study, this grouping will prove to be a convenient structure for aggregating results.

\subsection{Risk model modification}

With the insight gained through the initial phase of the HSS-3 project, the baseline HSS-2 risk influence model was restructured and updated. The principal modifications for the frequency model are described briefly below, and indicated with bold frames in Figure 2. Changes in the consequence model are not addressed in this paper.

- The main cause Aircraft technical dependability has been reorganised and reduced to two RIFs in order to achieve a clearer distinction between the manufacturing and the continuous airworthiness of helicopters.

- Passenger performance has become a separate RIF due to the possible impact from passengers on safety, usually in the form of passengers not following procedures. For instance, there have been occurrences of loose objects (e.g. newspapers) flying into the engine. Another example is passengers passing the tail rotor, exposing themselves for tail rotor strike.

- Aerodromes and ATM has become a separate main cause instead of being a part of Other conditions, reflecting that air traffic management is common to address as a possible main cause when analysing aircraft accidents.

- The RIF Heliport/helideck has been split into two RIFs (Heliport and Helideck) due to the contextual difference of the landing/take-off operation and the emphasis on helideck improvements.

- The former RIF Environment, representing what is left from the main cause Other conditions, has been split into the two RIFs Weather conditions and Other activities (including other air traffic, bird strike, surrounding facilities, etc.).

- The organisational RIF Other is included to address other organisations that may influence the probability of an accidental occurrence. Risk contributions from e.g. military activity (both na- 
tional and international) and other aircraft operators are captured by this RIF. 


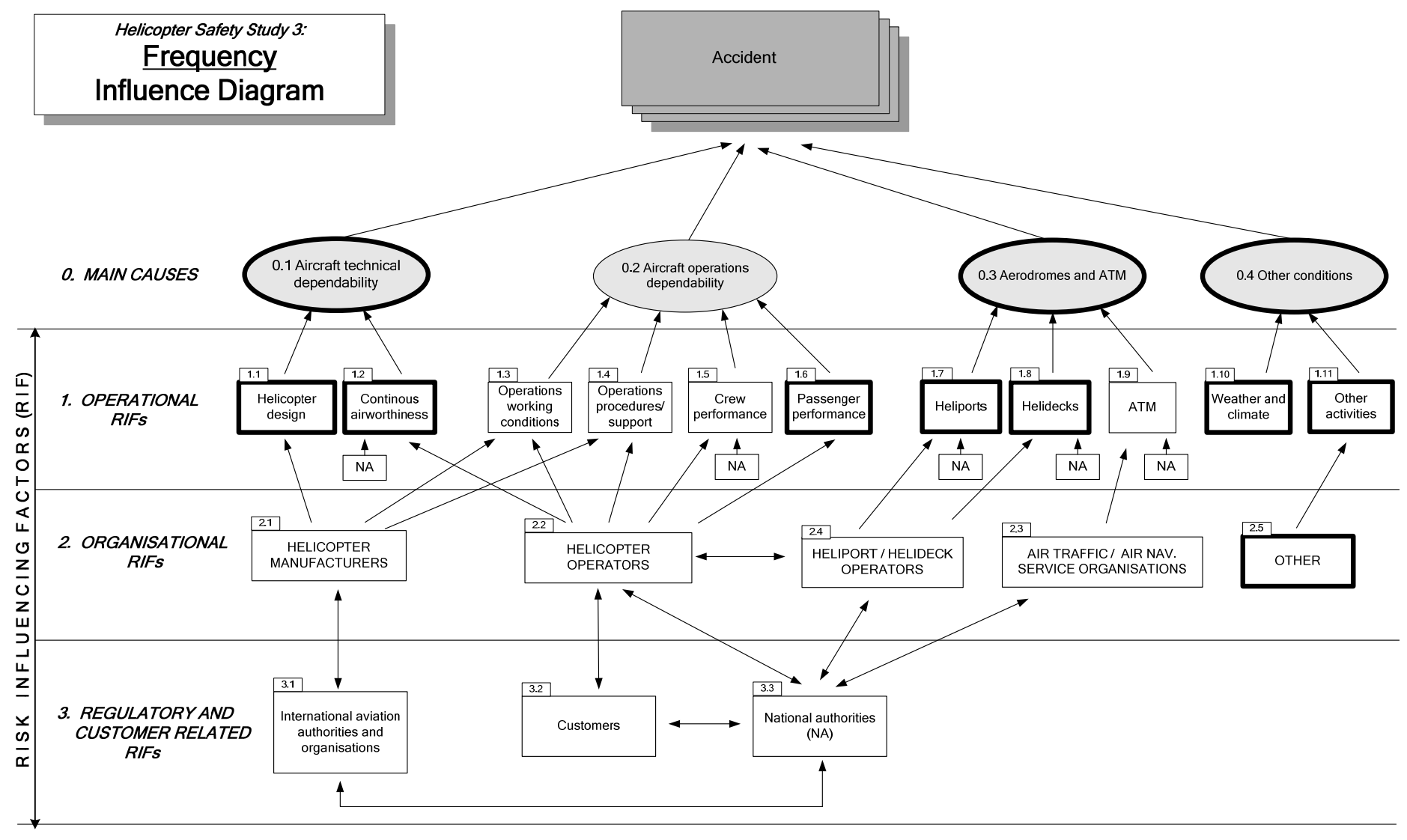

Figure 2. Influence diagram for the frequency of accidents/incidents. Recent modifications are indicated with bold frames.

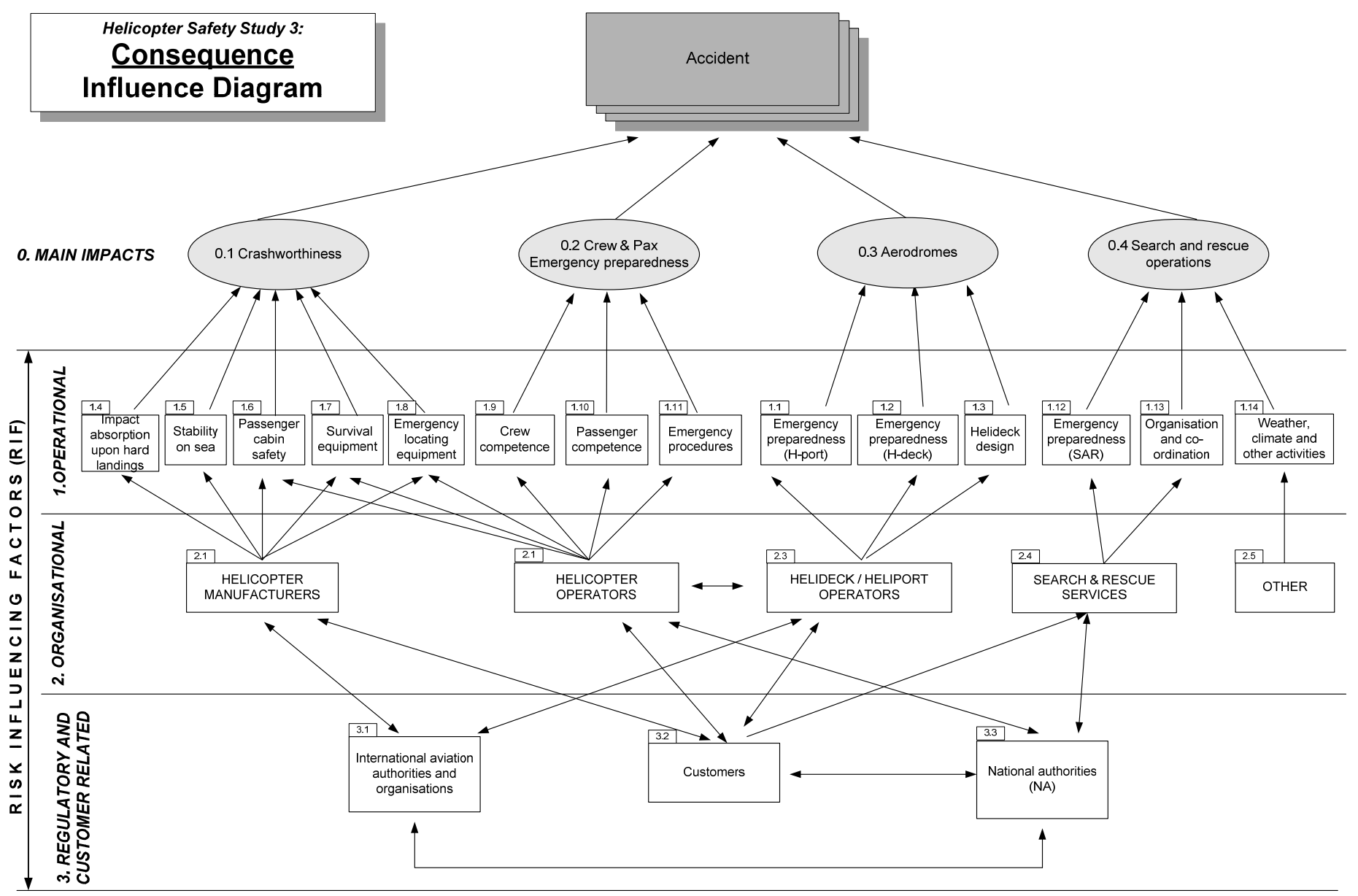

Figure 3. Influence diagram for the consequences of accidents/incidents. 


\subsection{Risk quantification}

Starting at the top of the diagram in Figure 1, the risk is quantified as the product of the frequency $(f)$ of accidents and their average consequence $(C)$, i.e. risk $=f \times C$. In the present study, $f$ is measured as the number of accidents per million person flight hours and $C$ is measured in numbers of fatalities per accident. Hence risk is measured as the number of fatalities per million person flight hours.

The risk contribution of an operational RIF to an accident is the product of two parts: the status and the weight of the RIF. These terms are defined as follows:

- The contribution of an operational RIF to an accident is the probability that an accident caused by the RIF will occur during one flight hour.

- The status of an operational RIF is the probability that the RIF is observed to have a "bad state" during one flight hour, i.e. the probability that a deviation caused by the RIF will occur during one flight hour.

- The weight of an operational RIF is the probability that an accident will occur during one flight hour given that the RIF has a "bad state".

The risk contribution from the organisational, regulatory and customer related RIFs (levels 2 and 3 ) is assessed by first weighing their influences on the operational RIFs. Combining the weights and the risk contribution of the operational RIFs, gives the risk contribution from RIFs further down in the RIF hierarchy. The assessment of weights is difficult at these levels, since the RIFs are complex and more vaguely defined. However, a coarse assessment of risk contribution is sufficient for comparing RIFs at the same level in order to identify focus areas for risk reducing measures.

Observe that the weights are often expected to be fixed in time, i.e. they are not changed when operational conditions are changed or risk reducing measures are introduced. So, risk-reducing measures are mainly expected to improve the status of a RIF. The assessment of RIF status is discussed in the remainder of the paper.

\section{EFFECT ON RISK INFLUENCING FACTORS}

The recent changes identified and described in section 2 affect the safety level in various ways. We study helicopter risk by means of the risk influencing model, so the effect of changes is related directly to the RIFs in the model. Each change is linked to one or more RIFs, with the result that each RIF is linked to a small set of changes, varying from zero to a handful.
The coupling of RIFs and changes are shown in Figures 4-6. In the figures, only the RIFs for frequency are shown. The RIF-diagram is split into 5 parts for clarity. Figure 4 shows the operational RIFs (level 1), while Figure 5 and Figure 6 show organisational RIFs (level 2) and customer/regulatory RIFs (level 3) respectively. For each RIF, all relevant associated developments are listed. In the figures, the numbers refer to the enumeration of changes described in section 2, and a short name is included to ease recognition. The changes that from a preliminary evaluation are believed to be most important are in boldface.

Concerning the consequence model, a similar coupling between changes and RIFs has been made, but this is not shown here due to space restrictions. Also, by far most changes are relevant for frequency RIFs, fewer are relevant for consequence RIFs. This reflects the general attitude towards preventing accidents from happening rather than limiting the consequences of accidents.

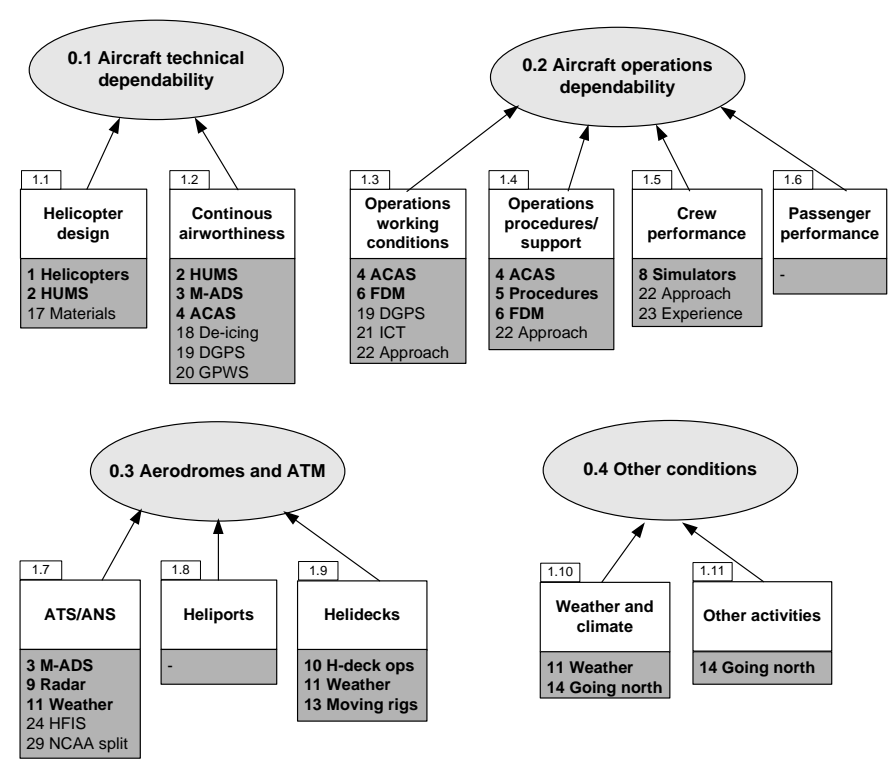

Figure 4. Operational RIFs and associated developments. The most important developments are in boldface.

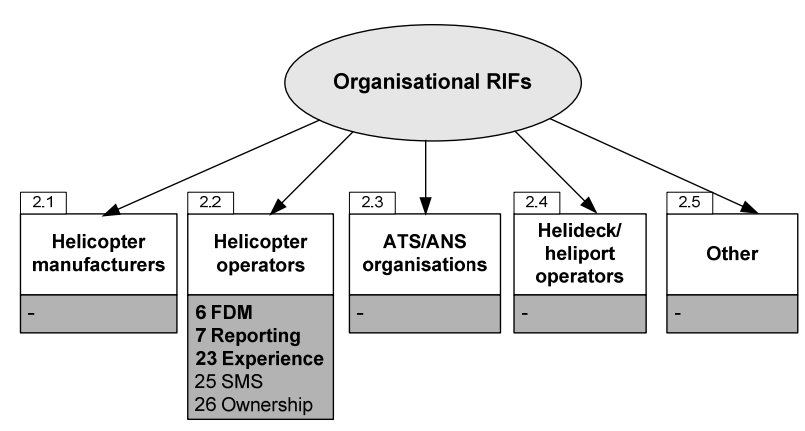

Figure 5. Organisational RIFs and associated developments. The most important developments are in boldface. 


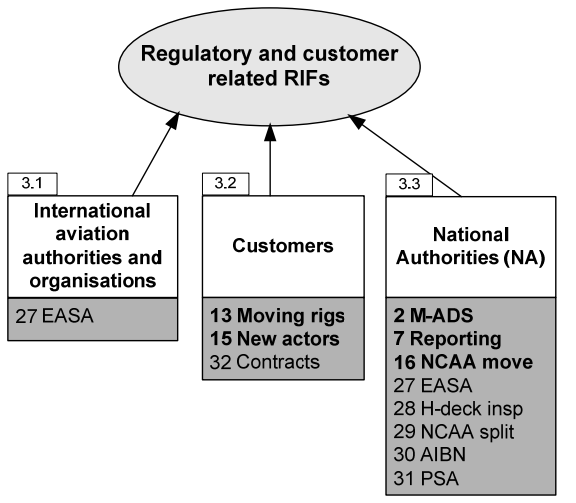

Figure 6. Regulatory and customer related RIFs and associated developments. The most important developments are in boldface.

Having established the relations between changes and RIFs, the next step will be to estimate the change in status for each RIF. This will be achieved through expert judgment sessions. Experts will take the development information into account and combine this with data and other information to give an overall assessment of the RIF status change in the study period.

\section{METHODICAL CHALLENGES}

Experts face a number of challenges when assessing the effect of changes in the study period. First of all, several changes may affect a single RIF (this is most often the case, cf. Figures 4-6), and finding the combined effect is not straightforward. Changes with positive effects may cancel out changes with negative effect, leaving the RIF status unchanged, even though there might be a considerable amount of development related to the RIF. In addition, the combination of certain changes may give non-linear and unpredictable interaction effects.

When assessing the effect of changes in the study period, it is of great importance when and how the changes are taking place. Figure 7 illustrates some central challenges related to the timing of changes. The nature of the challenges is described in the caption. In the graphs the $\mathrm{x}$-axis shows time, particularly the study period 1999-2008 (marked 99 and 08), while the y-axis measures effect of a certain change. The letter $c$ on the $\mathrm{x}$-axis marks the point in time where a change is initiated. The shaded areas under the graphs thus reflect various forms of "accumulated impact" a change may have during the study period. a) Point in time
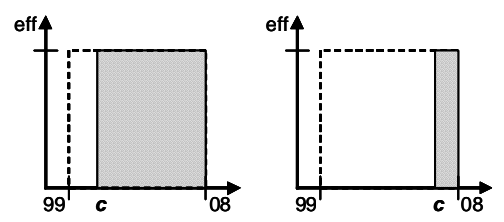

c) Gradual effect
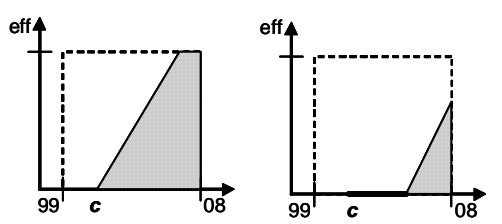

b) Delayed effect

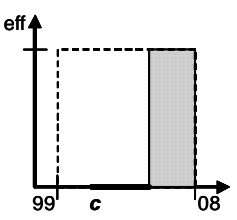

d) Continuous change

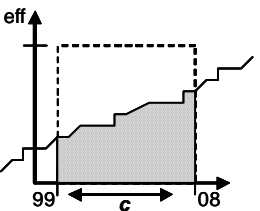

Figure 7. Challenges related to timing when determining the effect of changes in the study period 1999-2008. a) Point in time: Generally, a development taking place late in the period (i.e. close to 2008) will have a lower impact during the period than a development taking place early in the period (i.e. closer to 1999). b) Delayed effect: Upon initiation of a change, mechanisms of various sorts may delay the effect of the change, even to after the end of the period. c) Gradual effect: Both for changes with instant and delayed effect, the effect may appear gradually over a prolonged period of time. d) Continuous change: Helicopter development is to a large degree characterized by continuous improvement. For some changes it is impossible to identify a clear start and end point. This makes it impossible to assess the "level of development" at fixed points in time (e.g. at the start and end points of the study period).

\section{CONCLUSIONS}

The Helicopter Safety Study 3 (HSS-3) has conducted a comprehensive review of relevant literature and studies, accident/incident/deviation reports and statistics from the period 1999-2008, as well as interviews with key participants in the industry. This has provided an overview of recent developments relevant for helicopter safety for personnel in the Norwegian offshore industry.

The developments are linked to risk influencing factors (RIFs) in a risk influence model. Expert judgment will then be used to assess the risk contribution from each RIF to the total risk, thereby providing a means for focusing risk reducing measures.

There are a number of challenges related to the assessment of risk contribution from the RIFs. These challenges relate mostly to the timing of changes and the combined effect of changes.

The insight gained through the initial phase of the project has led to a number of modifications of the risk influence model inherited from the previous helicopter safety study (HSS-2). The major contribution is that we have harmonised the technological, human and organisational contribution to the risk picture.

HSS-3 will also consider new developments in safety theories, and study risk in a resilience engineering perspective. New theories address safety as a phenomenon that emerges from complex dynamic 
systems that are not amenable by simple causal explanations. The results from this approach will complement the results from the more "traditional" risk influence modeling approach described in this paper.

\section{ACKNOWLEDGEMENTS}

The Helicopter Safety Study 3 is sponsored by the Norwegian Oil Industry Association, with the following contributing industry partners: BP, ConocoPhillips, Eni, Gaz de France, Marathon, Nexen, Shell, StatoilHydro and Total. We would like to thank all technical, operative and administrative personnel from helicopter operators, air navigation providers and authorities for their constructive comments and openness in the best interest to improve helicopter safety. We also thank the other members of the project team, Per Hokstad and Erik Jersin, for their significant contributions.

\section{ABBREVIATIONS}

$\begin{array}{ll}\text { ACAS } & \text { Airborne Collision Avoidance System } \\ \text { AIBN } & \text { Accident Investigation Board, Norway } \\ \text { ATC } & \text { Air Traffic Control } \\ \text { ATM } & \text { Air Traffic Management } \\ \text { BORA } & \text { Barrier Analysis and Operational Risk Analysis } \\ \text { EASA } & \text { European Aviation Safety Agency } \\ \text { EHSAT } & \text { European Helicopter Safety Analysis Team } \\ \text { FDM } & \text { Flight Data Monitoring } \\ \text { GPS } & \text { Global Positioning System } \\ \text { GPWS } & \text { Ground Proximity Warning System } \\ \text { HFIS } & \text { Helicopter Flight Information Service } \\ \text { HMS } & \text { Helideck Monitoring System } \\ \text { HSS } & \text { Helicopter Safety Study } \\ \text { HUMS } & \text { Health and Usage Monitoring System } \\ \text { ICAO } & \text { International Civil Aviation Organisation } \\ \text { ICT } & \text { Information and Communication Technology } \\ \text { JHSAT } & \text { Joint Helicopter Safety Team } \\ \text { M-ADS } & \text { Modified Automatic Dependent Surveillance } \\ \text { NA } & \text { National Authorities } \\ \text { NCAA } & \text { Civil Aviation Authority, Norway } \\ \text { NCS } & \text { Norwegian Continental Shelf } \\ \text { PSA } & \text { Petroleum Safety Authority, Norway } \\ \text { RIF } & \text { Risk Influencing Factor } \\ \text { SAR } & \text { Search and Rescue } \\ \text { SMS } & \text { Safety Management System } \\ \text { VHM } & \text { Vibration Health Monitoring } \\ & \end{array}$

\section{REFERENCES}

Hansen, G.K., Hokstad, P. \& Sneltvedt, J. 1999. A risk influence model for helicopter traffic. In: Schuëller, G.I. \& Kafka, P. (eds.), Safety and Reliability: 1267-1272. Rotterdam: Balkema. (ESREL '99)

Hokstad, P. \& Dahle, E. 1998. A risk influence model applied to Norwegian domestic ferry traffic. In: Lydersen, S., Hansen, G.K. \& Sandtorv, H. (eds.), Safety and Reliability: 1119-1126. Rotterdam: Balkema. (ESREL '98)

Hokstad, P., Jersin, E., Hansen, G.K., Sneltvedt, J., \& Sten, T. 1999. Helicopter Safety Study 2. SINTEF Report no. STF38 A99423.

Hokstad, P., Jersin, E. \& Sten, T. 2001. A risk influence model applied to North Sea helicopter transport. Reliability Engineering and System Safety 74: 311-322.

Howard, R.A. \& Matheson, J.E. 2005. Influence Diagrams. Decision Analysis 2(3): 127-143.

Ingstad, O., Rosness, R., Sten, T., Ulleberg, T., Rausand, M. \& Lydersen, S. 1990. Helicopter Safety Study. Main Report. SINTEF Report no. STF75 A90008.

Røed, W., Mosleh, A., Vinnem, J.E., Aven, T. 2009. On the use of the hybrid causal logic method in offshore risk analysis. Reliability Engineering and System Safety 94: 445455.

Sklet, S., Aven, T., Hauge, S., Vinnem, J.E. 2005. Incorporating human and organisational factors in risk analysis for offshore installations. In: Kolowrocki, K. (ed.), Advances in Safety and Reliability: 1839-1847. Leiden: Balkema. (ESREL 2005) 